\title{
Penfigoide gestacional: relato de caso e a importância do diagnóstico precoce
}

\section{Pemphigoid gestationis: a case report and the importance of early diagnosis}

Karine Paschoal Botelhoํ. Caroline Braga Barrosoํ․ Igor Santos Costa ${ }^{2}$. Heitor de Sá Gonçalves ${ }^{3}$. Maria Araci Pontes ${ }^{4}$.

1 Médica residente de dermatologia do Centro de Dermatologia Dona Libânia, Fortaleza, Ceará, Brasil. 2 Patologista, Sócio do Laboratório Argos, Fortaleza, Ceará, Brasil. 3 Dermatologista, Diretor geral do Centro de Dermatologia Dona Libânia, Fortaleza, Ceará, Brasil. 4 Dermatologista, Diretora técnica do Centro de Dermatologia Dona Libânia, Fortaleza, Ceará, Brasil.

\section{RESUMO}

O penfigoide gestacional é uma rara dermatose bolhosa autoimune específica da gravidez. Acredita-se que anticorpos ataquem antígenos epidérmicos específicos e provoquem a separação da junção dermoepidérmica da pele e a formação de bolhas. O quadro em geral se inicia com placas eritematosas pruriginosas periumbilicais com posterior disseminação pelo corpo e evolução para lesões bolhosas. Acomete principalmente primíparas no segundo ou terceiro trimestre e costuma responder bem ao tratamento com corticoide sistêmico. Exame histopatológico e imunofluorescência direta são fundamentais para o diagnóstico. Há risco de efeitos adversos fetais, como baixo peso ao nascer e parto prematuro. Relatamos um caso de uma paciente com quadro exuberante no final do terceiro trimestre com excelente resposta ao tratamento e com nascimento de recém-nascido a termo e saudável.

Palavras-chave: Penfigoide gestacional. Dermatologia. Autoimunidade. Complicações na gravidez.

\section{ABSTRACT}

Pemphigoid gestationis is a rare autoimmune blistering dermatosis of pregnancy. It is believed that antibodies cause the separation of the dermal-epidermal junction of skin and blister formation. The disease usually starts with very itchy erythematous plaques around the umbilicus with subsequent dissemination throughout the body. It affects mainly pregnant women in the second or third trimester of their first pregnancy and usually responds well to treatment with systemic corticosteroids. Histopathology and direct immunofluorescence are essential for diagnosis. There is risk of adverse fetal effects, such as low weight and premature birth. We report a case of a patient with great skin involvement whose injuries began late in the third trimester with excellent response to treatment. She delivered a term healthy child.

Keywords: Pemphigoid gestationis. Dermatology. Autoimmunity. Pregnancy complications.

Autor correspondente: Karine Paschoal Botelho, Rua Henriqueta Galeno, 520, apartamento 1201, Bairro Dionísio Torres, Fortaleza, Ceará. CEP: 60135-420.Telefone: +55 85 98826-8528. E-mail: kpaschoalbotelho@yahoo.com.br

Conflito de interesses: Não há qualquer conflito de interesses por parte de qualquer um dos autores.

Recebido em: 22 Fev 2017; Revisado em: 24 Mar 2017; Aceito em: 29 Abr 2017. 


\section{INTRODUÇÃO}

A gravidez é um período de grandes mudanças, pois alterações imunológicas, metabólicas, endócrinas e vasculares trazem repercussões em todo o organismo, incluindo a pele. Tais alterações são classificadas como fisiológicas ou como dermatoses específicas da gravidez, sendo estas últimas alterações que ocorrem somente na gestação e por ela são desencadeadas. O penfigoide gestacional (PG) é um exemplo. Trata-se de uma dermatose bolhosa rara e autolimitada, de natureza autoimune. ${ }^{1}$ Estima-se uma incidência de 1:50.000 a 1:60.000 casos por gravidez. ${ }^{1,2}$

A incidência do PG parece estar relacionada a uma maior expressão de MHC classe II. HLA-DR3 é encontrado em 60 a $80 \%$ das pacientes, HLA-DR4 em $50 \%$ e a expressão de ambos é encontrada em $45 \%$ das pacientes. Acredita-se que a associação deste fator genético ao fator ambiental (gravidez) esteja envolvida com a patogênese da doença. ${ }^{3}$

O principal antígeno no PG é o colágeno XVII, também conhecido como BP 180. Trata-se de uma proteína presente na membrana basal placentária e na junção dermoepidérmica da pele. Acredita-se que uma expressão anormal de moléculas MHC classe II na placenta expõe o sistema imune materno a este antígeno e a consequente produção de autoanticorpos principalmente da classe IgG. Esses anticorpos ativam a via clássica do complemento, se depositam na membrana basal e provocam ativação e degranulação de eosinófilos. ${ }^{2,3} \mathrm{O}$ processo final resulta na separação da junção dermoepidérmica e consequente formação de bolhas. ${ }^{4}$

Os achados histopatológicos do penfigoide gestacional incluem espongiose (alguns casos com espongiose eosinofílica) ou vesícula intraepidérmica; edema acentuado da derme papilar, geralmente contendo bolha subepidérmica e linfócitos perivasculares com eosinófilos. A imunofluorescência direta (IFD) mostra depósitos lineares de IgG e complemento (C3) na zona de membrana basal. Imunofluorescência indireta geralmente é positiva para anticorpos circulantes na região da membrana basal. ${ }^{5}$

O quadro clínico normalmente se desenvolve no segundo ou no terceiro trimestre da gestação, em primíparas, mas também há casos descritos de início no primeiro trimestre e no pós-parto imediato. ${ }^{3,6,7}$ É rara a manifestação com lesões disseminadas. ${ }^{6}$ A idade média das pacientes acometidas é de 30 anos. $^{7}$ A doença tende a recorrer em gestações subsequentes e, nesses casos, é mais precoce e mais grave. É comum haver exacerbações no pós-parto. ${ }^{3}$ Neste artigo, relatamos o caso de uma primípara jovem com manifestações exuberantes iniciadas no terceiro trimestre da gestação.

\section{DESCRIÇÃO DO CASO}

Paciente, feminina, branca, 17 anos, primigesta, no $3^{\circ}$ trimestre de gestação, com 35 semanas de idade gestacional, acompanhada em pré-natal de baixo risco, há 3 semanas, vinha evoluindo com uma lesão eritematosa e pruriginosa inicialmente em coxa direita que, há 2 semanas, se disseminaram pelo corpo e houve aumento do prurido. Procurou atendimento médico e foi internada para investigação diagnóstica. Negava uso de qualquer medicação previamente ao aparecimento do quadro.

Ao exame admissional, apresentava sinais vitais normais e a presença de pápulas e placas urticariformes e descamativas disseminadas em membros superiores, coxas, mamas, abdome e, como mostra a Figura 1, no dorso. Havia bolha tensa com conteúdo citrino em antebraço direito e vesícula em pé esquerdo. Chamava a atenção o acometimento confluente de toda a região abdominal (Figura 2). Os exames laboratoriais mostraram eosinofilia, aumento de PCR, VDRL não reagente, FAN reagente 1:320 padrão citoplasmático pontilhado reticulado, sorologias para as hepatites B e C não reagentes, sorologias para toxoplasmose, CMV e rubéola $\mathrm{IgG}$ reagentes e sorologia para herpes simples não reagente.

Figura 1. Placas urticariformes e descamativas em dorso.

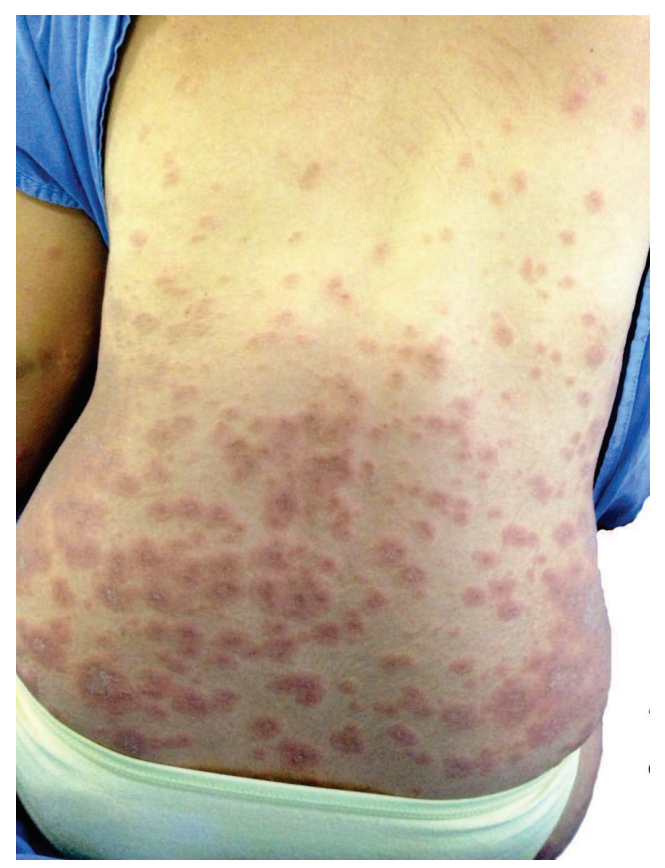

Figura 2. Lesões confluentes na região abdominal e acometimento de coxas.

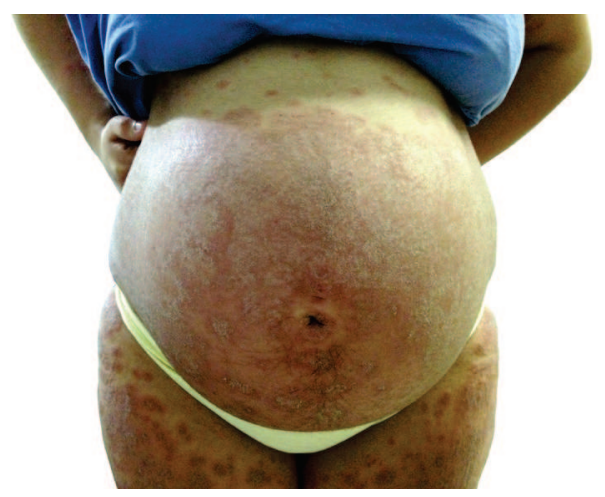


Foi realizada biópsia da bolha em antebraço direito que revelou epiderme com acantose leve, espongiose difusa, formação de vesículas intraepidérmicas e fenda subepidérmica rica em eosinófilos, derme com infiltrado linfocitário e eosinofílico. A imunofluorescência direta (IFD) da pele evidenciou positividade forte e linear para $\mathrm{C} 3$ na zona da membrana basal epidérmica, fechando o diagnóstico de penfigoide gestacional (Figura 3).

Paciente foi tratada com prednisona na dose de $0,5 \mathrm{mg} / \mathrm{kg} / \mathrm{dia}$ e anti-histamínico oral com remissão do quadro dermatológico e do prurido, sendo então iniciado desmame da corticoterapia (Figura 4). Após o parto, porém, houve recorrência das lesões com controle efetivo após início da mesma dose de prednisona prescrito na gestação. O recém-nascido não foi acometido pela doença, nasceu a termo, parto normal, sem intercorrências. Cinco meses após o parto, paciente apresentava apenas hipercromia residual nos locais onde anteriormente havia lesões (Figura 5).

Figura 3. Placas urticariformes e descamativas em dorso.

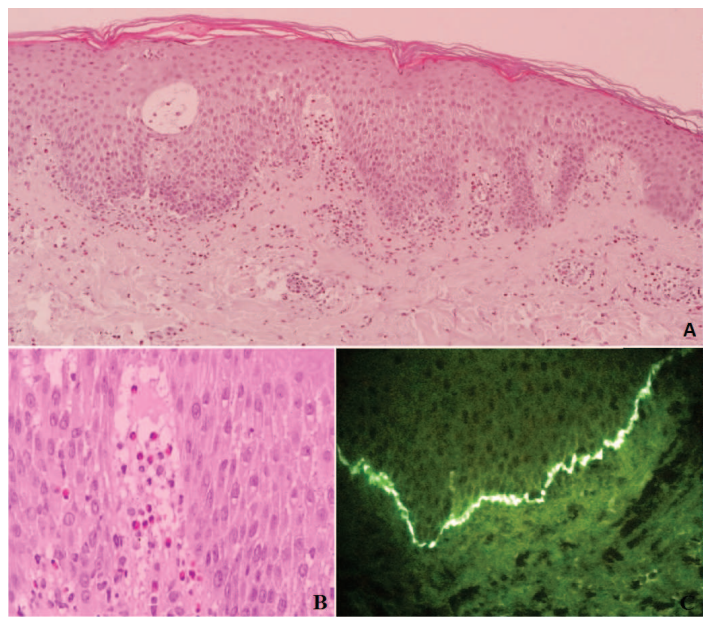

Figura 4. Melhora das lesões durante o tratamento com prednisona.

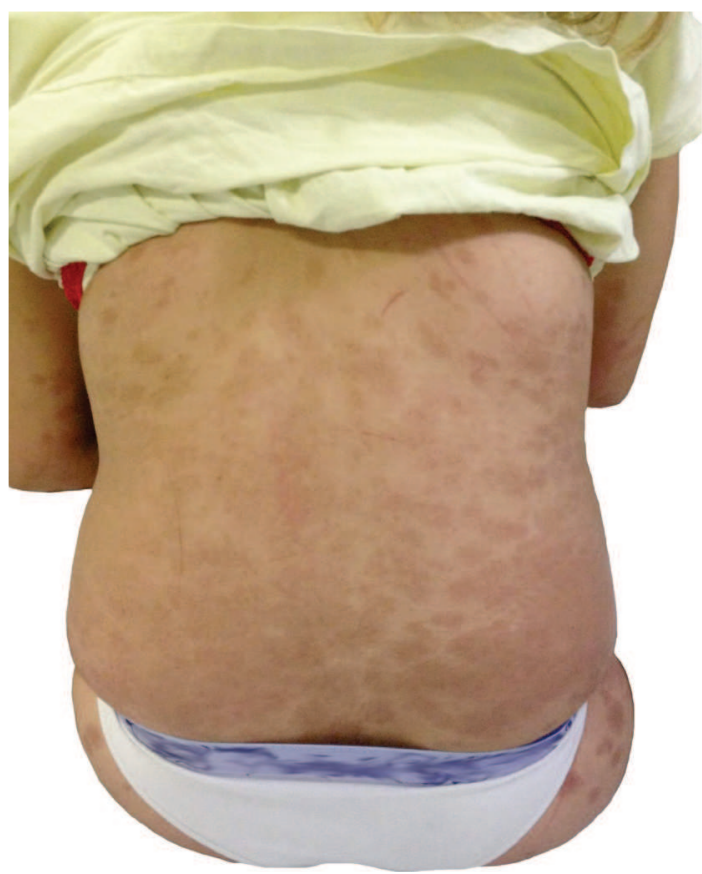

Figura 5. Cinco meses após o parto, paciente apresentava apenas hipercromia residual onde anteriormente havia lesões de pele.

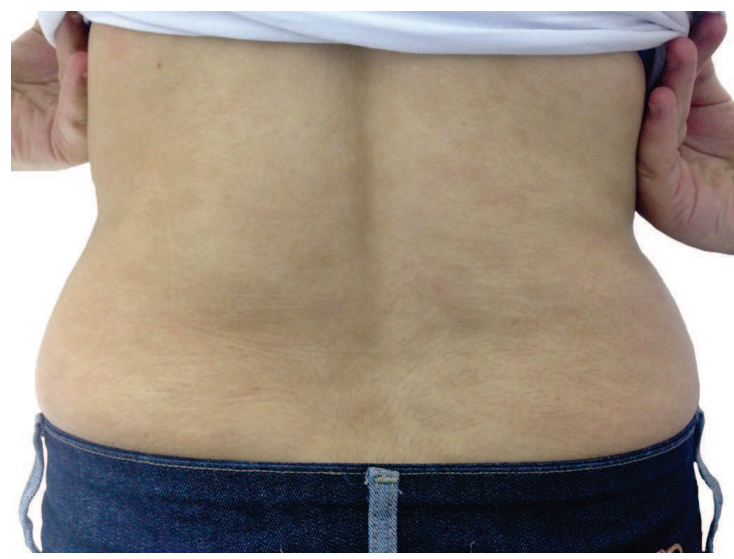

\section{DISCUSSÃO}

Em dermatologia, o termo "penfigoide" é usado para descrever doenças bolhosas, mas, na verdade, a maioria dos casos de PG não é bolhosa e se apresenta como placas e pápulas urticariformes e do tipo eczema, sem o comprometimento de mucosas. $^{8}$ A região periumbilical é o primeiro sítio envolvido em $81 \%$ dos casos. ${ }^{1}$ As lesões são pruriginosas e podem progredir rapidamente para abdome, dorso, tórax e extremidades, apresentando-se de forma policíclica ou anular. ${ }^{4}$

A paciente relatada, porém, apresentou inicialmente as lesões na coxa que posteriormente se disseminaram pelo corpo. Além disso, era mais jovem que a idade média de acometimento descrito na literatura.

O prurido é uma alteração cuja etiologia pode ser tanto decorrente de alterações fisiológicas ou fazer parte de um quadro de dermatose específica da gravidez. O prurido fisiológico ocorre comumente no abdome, durante o terceiro trimestre, e também no ânus, vulva e couro cabeludo. Por outro lado, o prurido pode ser manifestação precoce de dermatoses específicas da gestação como o penfigoide gestacional. ${ }^{9}$

Várias investigações laboratoriais estão disponíveis para confirmar o diagnóstico da doença. Os exames de rotina incluem histopatologia e IFD, que detecta, na zona de membrana basal, C3 em 70 a $75 \%$ dos casos e IgG, em 25 a 30\%, e é o padrão ouro para o diagnóstico de PG. Além disso, pode-se realizar investigações adicionais como imunofluorescência indireta e ELISA. Em conjunto, os critérios clínicos e laboratoriais são utilizados para o diagnóstico definitivo da doença. ${ }^{7}$

O principal diagnóstico diferencial é a erupção polimorfa da gravidez, a mais comum das dermatoses gestacionais, com prevalência de 1 caso para cada 160 gestações. Esse quadro costuma acometer primíparas no terceiro trimestre da gestação. Inicia-se como lesões urticariformes intensamente pruriginosas, ao redor das estrias abdominais, com posterior disseminação pelo corpo. O histopatológico é semelhante ao do PG, mas a IFD é negativa. Ela é uma doença benigna, de resolução espontânea e sem nenhum risco fetal. ${ }^{1,6}$ Outros 
diagnósticos diferenciais são o penfigoide bolhoso, a dermatite herpetiforme e o eritema multiforme. ${ }^{2}$

Os casos leves de PG respondem a corticosteroides tópicos potentes e anti-histamínicos. Entretanto, a maioria dos casos exige tratamento sistêmico. Os corticosteroides orais são a terapêutica de primeira linha, em geral com uso de prednisona na dose de $0,5 \mathrm{mg} / \mathrm{kg} / \mathrm{dia}$. Durante o período periparto, a dose do corticoide deve ser elevada para prevenir a exacerbação comum que ocorre no pós-parto. ${ }^{10}$

Corticoterapia é considerada terapia segura na gravidez, e não costuma ter efeitos adversos sobre o resultado da gravidez. ${ }^{11}$ Alguns casos, entretanto, constituem um verdadeiro desafio, pois a terapia sistêmica com corticoide pode não ser efetiva. Há relatos na literatura de opções terapêuticas com tetraciclinas e nicotinamida, ciclofosfamida, ciclosporina, azatioprina, dapsona, imunoglobulina humana, rituximab e plasmaférese. Entretanto, os dados de tratamento de PG grave usando medicações imunossupressoras são escassos, e deve ser bem pesado qual o risco que a medicação pode proporcionar ao feto em relação aos benefícios adquiridos pela mãe. ${ }^{12}$

No PG, apesar de pouco frequentes, são descritos possíveis efeitos adversos relacionados à gestação: risco aumentado de morte fetal, de aborto espontâneo e de supressão do eixo hipotalâmico-hipofisário. ${ }^{13}$ Além disso, outros efeitos adversos são próprios e comuns ao uso crônico de corticoide sistêmico como hipertensão, síndrome de Cushing, osteopenia e osteoporose. ${ }^{11}$

Estima-se que 5 a $10 \%$ dos bebês de mães acometidas podem nascer com lesões bolhosas devido a transferência placentária

\section{REFERÊNCIAS}

1. Alves GF, Nogueira LS, Varella TC. Dermatologia e gestação. An Bras Dermatol. 2005;80(2):179-86.

2. Lipozenčić J, Ljubojevic S, Bukvić-Mokos Z. Pemphigoid gestationis. Clin Dermatol. 2012;30(1):51-5.

3. Engineer L, Bhol K, Ahmed AR. Pemphigoid gestationis: a review. Am J Obstet Gynecol. 2000;183(2):483-91.

4. Lardenoije CM, van de Water M, Mertens HJ, Gondrie ET. Pemphigoid gestationis. BMJ Case Rep. 2011;2011.

5. Rapini RP. Dermatopatologia prática. Rio de Janeiro: Dilivros, 2007. Capítulo 06, Doenças vesiculosas subepidérmicas; p. 91-7.

6. Castro LA, Lundell RB, Krause PK, Gibson LE. Clinical experience in pemphigoid gestationis: report of 10 cases. J Am Acad Dermatol. 2006;55(5):823-8.

7. Tani N, Kimura Y, Koga H, Kawakami T, Ohata C, Ishii N, et al. Clinical and immunological profiles of 25 patients with pemphigoid gestationis. Br J Dermatol. 2015;172(1):120-9.

8. Soutou B, Aractingi S. Skin disease in pregnancy. Best Pract Res Clin Obstet Gynaecol. 2015;29(5): 732-40.

\section{Como citar:}

Botelho KP, Barroso CB, Costa IS, Gonçalves HS, Pontes MA. Penfigoide gestacional: relato de caso e a importância do diagnóstico precoce. Rev Med UFC. 2017 set-dez;57(3):73-76. de IgG. O quadro costuma se resolver espontaneamente em semanas e normalmente não requer tratamento. ${ }^{3}$ Mulheres com início da doença no primeiro ou segundo trimestre e aquelas em que há a formação de bolhas têm maior risco para repercussões fetais, tais como, baixo peso ao nascer e diminuição da idade gestacional no parto, inclusive com parto prematuro. Tais gestações devem ser consideradas de risco elevado e, portanto, ter acompanhamento rigoroso. O tratamento com corticoide não mostrou aumento do risco de eventos adversos fetais. ${ }^{14}$

É importante o conhecimento e diagnóstico precoce das dermatoses específicas da gravidez, principalmente o PG, por seu potencial de morbidade materna e fetal. Em especial é indispensável saber diferenciar o PG da erupção polimorfa da gravidez, a dermatose mais prevalente da gestação, pois esta não traz efeitos adversos para a mãe e para o feto.

Métodos complementares, como a IFD, são fundamentais nesses casos, pois a evolução clínica e os achados histopatológicos no PG podem mimetizar outras erupções cutâneas. Com o diagnóstico preciso, é possível um acompanhamento rigoroso da gravidez, detecção precoce de complicações fetais e aconselhamento quanto a gestações subsequentes, visto que o risco de desenvolver a doença e a gravidade do PG aumenta com a paridade da mulher.

Vale destacar, por fim, que uma abordagem por diferentes especialidades médicas é fundamental em doenças raras e com risco de complicações fetais, facilitando o diagnóstico, o manejo do caso e o sucesso terapêutico, além de minimizar desfechos desfavoráveis.

9. Fernandes LB, Mendonça CR, Amaral WN. Alterações dermatológicas na gravidez: revisão de literatura. Femina. 2014;42(2):101-8.

10. Marques AR, Monteiro L, Meneses M. Um caso de penfigóide gestacional. Rev Port Med Geral Fam. 2016;32(3):217-21.

11. Intong LR, Murrell DF. Pemphigoid gestationis: current management. Dermatol Clin. 2011;29(4):621-8.

12. Huilaja, L, Mäkikallio K, Hannula-Jouppi K, Väkevä L, HöökNikanne J, Tasanen K. Cyclosporine treatment in severe gestational pemphigoid. Acta Derm Venereol. 2015;95(5):593-5.

13. Gan DC, Welsh B, Webster M. Successful treatment of a severe persistent case of pemphigoid gestationis with antepartum and postpartum intravenous immunoglobulin followed by azathioprine. Australas J Dermatol. 2012;53(1):66-9.

14. Chi CC, Wang SH, Charles-Holmes R, Ambros-Rudolph C, Powell J, Jenkins R, et al. Pemphigoid gestationis: early onset and blister formation are associated with adverse pregnancy outcomes. Br J Dermatol. 2009;160(6):1222-8. 